CARTA INTERNACIONAL

ASSOCIAÇÃO BRASILEIRA DE RELAÇÕES INTERNACIONAIS

ISSN $2526-9038$

\title{
Geografia e arquitetura institucional da cooperacão ambiental brasileira na América do Sul ${ }^{1}$
}

\author{
Geography and institutional architecture \\ of the brazilian environmental \\ cooperation in south America
}

Geografía y arquitectura a institucional de la cooperación ambiental Brasileña en Sudamérica

DOI: $10.21530 /$ ci.v16n1.2021.1083

Ademar Pozzatti Henrique Rogovschi ${ }^{3}$

Copyright:

- This is an open-access article distributed under the terms of a Creative Commons Attribution License, which permits unrestricted use,

distribution, and reproduction in any medium, provided that the original author and source are credited.

- Este é um artigo publicado em acesso aberto e distribuído sob os termos da Licença de Atribuição Creative Commons, que permite uso irrestrito, distribuição e reprodução em qualquer meio, desde que $o$ autor $e$ a fonte originais sejam creditados.

\section{Resumo}

A partir das lentes da joint discipline que transpassa categorias de análise das disciplinas do Direito Internacional e das Relações Internacionais, a presente pesquisa radiografa a geografia e a arquitetura institucional da cooperação ambiental brasileira na América do Sul. Para radiografar a geografia, a pesquisa indaga onde esta cooperação está localizada, o que ela estabelece e quais

1 Pesquisa financiada com recursos do Edital Universal CNPq e do Edital ARD FAPERGS.

2 Doutor pelo Programa de Pós-Graduação em Direito da Universidade Federal de Santa Catarina - UFSC. Professor do Programa de Pós-Graduação em Direito (PPGD) e do Programa de Pós-Graduação em Relações Internacionais (PPGRI) da Universidade Federal de Santa Maria, Rio Grande do Sul, Brasil. (ademar. pozzatti@ufsm.br). ORCID: https://orcid.org/0000-0001-8552-1507. Os autores agradecem as contribuições dos revisores anônimos.

3 Estudante do Programa de Pós-Graduação em Relações Internacionais (PPGRI) da Universidade Federal de Santa Maria - UFSM, Rio Grande do Sul Brasil. (henriquejrogovschi@gmail.com). ORCID: https://orcid.org/0000-0002-5206-0510 Artigo submetido em 11/05/2020 e aprovado em 07/09/2020. 
são os atores cujos interesses a envolvem. Ao investigar a arquitetura, foca-se em entender como ela operacionaliza o seu conteúdo normativo, o que envolve compreender o papel do direito internacional em operar políticas públicas ambientais transversais a diversos Estados. A exploração documental analisa os regimes bilaterais na matéria, e, através de levantamento, sugere que esta cooperação é descentralizada e difusa, ao mesmo tempo que inova no seu modus operandi.

Palavras-chave: Cooperação Internacional; Meio-Ambiente; Direito Internacional; América do Sul; Transdisciplinaridade.

\begin{abstract}
From the lenses of the joint discipline that cuts across categories of analysis of the disciplines of International Law and International Relations, this investigation radiographs the geography and the institutional architecture of the Brazilian environmental cooperation in South America. By analyzing its geography, the study inquires where this cooperation is situated, what it establishes and which are the actors whose interests involve it. By investigating its architecture, it focuses on understanding how it operationalizes its normative content, which involves understanding the role of international law in operating environmental public policies that are transversal to different States. The documentary exploration analyzes bilateral regimes in this sector, and, through survey, suggests that this cooperation is decentralized and diffuse, while innovating in its modus operandi.
\end{abstract}

Keywords: International Cooperation; Environment; International Law; South America; Transdisciplinarity.

\title{
Resumen
}

Con base en los lentes de la joint discipline que atraviesa categorías de análisis de las disciplinas del Derecho Internacional y Relaciones Internacionales, esta investigación examina la geografía y la arquitectura institucional de la cooperación ambiental brasileña en América del Sur. Para radiografiar la geografía, la investigación se pregunta dónde se ubica esta cooperación, qué establece y cuáles son los actores cuyos intereses la involucran. Al investigar la arquitectura, se enfoca en comprender cómo opera su contenido normativo, lo que implica comprender el papel del derecho internacional en la operación de políticas públicas ambientales en varios Estados. La exploración documental analiza los regímenes bilaterales en la materia y, a través de un levantamiento, sugiere que esta cooperación es descentralizada y difusa, al mismo tiempo que innova en su modus operandi.

Palabras clave: Cooperación Internacional; Medio ambiente; Derecho internacional; América del Sur; Transdisciplinariedad. 


\section{Introdução}

O aprofundamento da globalização é um ponto de inflexão na história recente das relações internacionais sob diversos aspectos, tanto temáticos quanto operacionais. No aspecto temático, ela opera movimentos antagônicos, frequentemente concorrentes, visto que intensificou o comércio de bens e serviços, vulgarizou investimentos externos e, muito em função disto, expandiu a (des) regulação dos sistemas financeiros locais e regionais, ao mesmo tempo que acentuou desigualdades e conflitos nas esferas dos direitos humanos e ambientais. Neste cenário, a temática ambiental foi objeto de investigação de distintas perspectivas alocadas em diferentes unidades de análise, como aquelas relacionadas à segurança (Barnett e Adger 2007), ao desenvolvimento econômico (Queiroz 2011), à política externa (Fonseca 2011) e ao direito internacional (Dubois 2009).

Do ponto de vista operacional, essas questões são tratadas via cooperação internacional, institucionalizada por atos internacionais frutos de diversas instâncias normativas (Kennedy 2007). Para entender a complexidade deste fenômeno, as relações internacionais têm demandado mudanças no modus operandi do direito internacional, visto que ele cada vez mais envolve a atuação das instituições domésticas dos Estados para atingir, em nível local, as respostas aos desafios globais (Slaughter e Burke-White 2006). Assim, para além de um gerencialismo legislativo e judicial (Koskenniemi 2009), o direito internacional precisa projetar "programas de ação governamental voltados à concretização de direitos" (Bucci 2001, 13), a fim de atingir a mudança desejada na tutela ambiental.

Se historicamente a formação da politica externa brasileira esteve a cargo quase que exclusivamente do Itamaraty, atualmente ela tem dado protagonismo aos atores domésticos vinculados a outros Ministérios, os quais têm sido chamados cada vez mais a internacionalizar as políticas públicas das suas pastas (Dri 2016). Essa transnacionalização das políticas públicas, operada via cooperação internacional, é altamente institucionalizada, ainda que sejam raros os estudos acerca desse fenômeno nas disciplinas do Direito Internacional (DI) e das Relações Internacionais (RI) ou mesmo no âmbito de uma joint discipline (Slaughter, Tulumello e Wood 1998).

Para contribuir com o debate acerca do papel do direito internacional na governança ambiental regional, a presente pesquisa investiga como ele impulsiona a cooperação internacional e a transnacionalização de políticas públicas na matéria, a partir do levantamento dos atos internacionais firmados entre o 
Brasil e os demais países da América do Sul que estão em vigor. Ao investigar a geografia desta cooperação, quer-se entender onde ela está localizada e o que compõe o seu objeto, bem como quais instituições participam desses acordos. Por sua vez, explorar a arquitetura desta cooperação envolve entender como ela é operacionalizada e questionar os padrões através dos quais os atores a implementam. Entender esse modus operandi a partir de um referencial analítico transdisciplinar permitirá tirar lições sobre o papel do direito nesta empreitada.

Este artigo está estruturado em três seções. A primeira trata da delimitação teórica da investigação, quando são explorados os recursos analíticos da joint discipline (1). A segunda explica a metodologia da pesquisa e a geografia da cooperação analisada (2). A terceira seção debate os resultados obtidos, a fim de entender quais atores, ideias e instituições têm um papel na estruturação desta cooperação, e, através da análise desta arquitetura cooperacional, tenta inferir sobre o papel do direito neste processo (3).

\section{Diálogo entre as categorias de análise da joint discipline}

Analisar a geografia e a arquitetura da cooperação ambiental brasileira na América do Sul a partir dos atos internacionais que a institucionalizam envolve mobilizar referencial teórico tanto das RI quanto do DI. Não se trata de performar uma dupla empreitada de pesquisa, tentando trazer a política para gabaritar a disciplina jurídica, ou levando o direito para dar novo verniz à Teoria das Relações Internacionais, mas de desenvolver a análise proposta a partir de uma joint discipline (Slaughter, Tulumello e Wood 1998). Trata-se de entender alguns vocábulos comuns às duas disciplinas que são objeto desta pesquisa a partir de um conjunto analítico transdisciplinar, a fim de compreender o impacto do "direito internacional" no processo de fomentar, através da "cooperação", “políticas públicas”.

Na perspectiva que adotamos, a cooperação e o direito estão comprometidos com a transformação da realidade não porque "gerenciam" os Estados, mas porque, ao estimular o "enviesamento estrutural" (Koskenniemi 2009), participam do processo iterativo que (con)forma a política. Assim, para produzir a radiografia proposta, é necessário recorrer às categorias analíticas das RI, mas sem pressupor que a observação por si só é um fim, mas porque a precisão da análise de como o direito é utilizado pelos diversos atores para, através da cooperação, 
institucionalizar as suas propostas de resolução de problemas comuns, pode melhorar este processo ou até mesmo ser replicado por outros atores para resolver outros problemas. Em uma frase: o rigor analítico tem um forte componente normativo. E talvez esta seja o maior potencial transformador da joint discipline.

Na perspectiva da tradicional agenda dual, uma primeira preocupação comum às duas disciplinas era saber se - e não o nosso como - as regras promoviam mudanças nos comportamentos dos atores, o que ficou conhecido como "desafio realista” (Slaughter 1993). Apartando-se desse enfoque, este trabalho não se propõe a dar uma resposta empírica a este desafio a partir das micronarrativas institucionais da América do Sul. Igualmente, do ponto de vista da retórica jurídica, nosso objetivo não é resolver os problemas linguísticos do direito internacional, reforçando o gerencialismo “que sugere que os problemas internacionais [...] deveriam ser resolvidos através do desenvolvimento de vocabulários técnicos altamente complicados para a formulação de políticas institucionais” (Koskenniemi 2009, 084). Não se trata, portanto, de aprimorar a retórica do "Estado de direito internacional”, mas tão somente de conseguir extrair algumas lições de como o direito internacional opera para, através da cooperação, fomentar políticas públicas.

Em uma difusão teórica bastante conhecida no campo, os Estados se comportariam como os únicos atores racionais e atuariam no plano externo de acordo com suas preferências, em busca de poder. Nesta perspectiva, a inexistência de uma autoridade central no sistema internacional não limitaria a cooperação, visto que o auto interesse dos Estados orientaria as suas ações externas a fim de a alcançarem. Em meio a esta complexidade sistêmica, Axelrod e Keohane (1985) argumentam que o sucesso da cooperação dependeria de três variáveis centrais: mutualidade de interesses, número de jogadores e sombra para o futuro.

Quanto à mutualidade de interesses, os referidos autores afirmam que a estrutura de payoff influencia no alcance da cooperação, visto que a previsão da divisão dos custos possui relevância central para o sucesso do projeto. Quanto ao número de jogadores, eles afirmam que a percepção dos atores em relação aos outros é central para a persecução da cooperação, de forma que, para além dos fatores objetivos, os subjetivos também ganham importância. Por sua vez, a sombra para o futuro se refere às condições que permitem vislumbrar o futuro da cooperação, e têm como variáveis para sua análise os horizontes de longo prazo, a regularidade das apostas, a confiabilidade das informações sobre as

4 No original "that suggests that international problems [...] should be resolved by developing increasingly complicated technical vocabularies for institutional policy-making”. 
ações dos outros e o rápido feedback sobre mudanças nas ações dos outros (Axelrod e Keohane 1985).

A partir do momento que estas variáveis são institucionalizadas em um acordo internacional, "afetam as expectativas dos atores [...] [e] podem alterar a medida em que os governos esperam que suas ações possam afetar o comportamento dos outros em questões futuras" (Axelrod e Keohane 1985, 2345). Ao fomentar consenso, Keohane (2002) sustenta que as instituições passaram a ocupar um lugar chave na cooperação internacional, justamente porque alteram a percepção em relação ao futuro dos atores, modificam o payoff e reduzem os seus custos. Neste contexto, Slaughter (1993) mostra que Keohane redescobre o direito internacional justamente por ressaltar que a função das instituições é ajudar os governos a encalçarem seus objetivos via cooperação, ao invés de determinar o que eles devem fazer.

Contudo, o institucionalismo clássico encontra limites analíticos, entre outras razões, por não adentrar na membrana estatal e insistir em ganhos absolutos. No contexto ambiental, a maior complexidade do sistema internacional exigiu um alargamento do referencial analítico, visto que "os Estados pareciam estar imiscuídos em uma rede institucional em um sentido mais amplo, em regras implícitas e explícitas que contribuíam para a modificação do comportamento estatal" (Barros-Platiau, Varella e Scheleicher 2004, 110). Assim, estudiosos de inclinação liberal popularizaram a ideia de regimes como variáveis que interferiam tanto no poder do Estado quanto nos resultados internacionais (Keohane 2002).

Por serem "princípios, normas e regras implícitos ou explícitos e procedimentos de tomada de decisões de determinada área das relações internacionais em torno dos quais convergem as expectativas dos atores" (Krasner 2012, 94), os regimes configuram estruturas de cooperação que superam os arranjos temporários. Esta ideia ajuda a entender os diversos regimes ambientais, os quais se caracterizam por um maior dinamismo quanto à sua estrutura de organização, da mesma forma que alarga as potencialidades de entender o modus operandi do direito em implementar a cooperação, pois ao focar em regras e procedimentos, torna-o um processo, e não um dado. Para Slaughter, Tulumello e Wood (1998), esta poderia ser justamente a maior contribuição da joint discipline: qualificar o direito internacional como um processo de articulação político-institucional que mobiliza peças dos tabuleiros internacionais e domésticos.

5 No original: "affect actors' expectations. Thus institutions can alter the extent to which governments expect their present actions to affect the behavior of others on future issues". 
Nesse sentido, para compreender os fins do direito internacional, torna-se necessário entender a dinâmica da sua criação. Segundo Abbott (1989, 4086), as lentes das RI emprestam rigor analítico a esta empreitada, visto que permitem compreender as "condições estruturais que favorecem ou entravam a cooperação internacional”, as “técnicas através das quais os Estados buscam alcançar cooperação e cumprimento dos acordos, dentro das condições existentes” e as “estratégias através das quais os Estados conseguem modificar condições prevalentes e melhorar as possibilidades de cooperação”.

De fato, esta abordagem "realista” do direito internacional é um importante ponto de inflexão na empreitada de uma joint discipline, pois evidencia a dimensão doméstica tanto da cooperação quanto do direito internacional. Se o direito internacional busca responder a problemas que surgem dentro dos Estados, há de se entender o processo pelo qual um determinado problema, ou demanda, acaba por se tornar pauta para a sua ação. Nessa seara, inspirados pelos elementos descritos por Abbott (1989), pode-se utilizar do modelo formulado por Pozzatti e Farias (2019), para pensar quais variáveis interagem na transformação da demanda doméstica em ação do direito internacional. Para os autores,

três variáveis distintas interagem nesse processo: o problema, a solução, e a política - ou processo político. Nessa interação, os atores são responsáveis por perceber e interpretar um problema, e por pensar uma solução, que é a política pública, que deverá passar por processos políticos nas instâncias responsáveis por realizá-la (Pozzatti e Farias 2019, 367).

Estes processos políticos operam circularmente nos tabuleiros internacionais e domésticos, razão pela qual o direito internacional passa na atualidade por uma reorganização dos mecanismos pelos quais opera. Isso porque "se as regras respondem a problemas concretos, e há uma nova geração de problemas mundiais que surgem de dentro dos Estados e não da sua ação interestatal" (Pozzatti e Farias 2019, 365), "para oferecer uma resposta eficaz a esses novos desafios, o sistema jurídico internacional deve ser capaz de influenciar as políticas domésticas dos Estados e aproveitar as instituições nacionais na busca de objetivos globais” (Slaughter e Burke-White 2006, 328, tradução nossa7).

6 No original: "structural conditions that favor or hinder international cooperation [...]; techniques by which states seek to achieve cooperation and compliance under existing conditions [...]; strategies through which states can modify prevailing conditions and improve the possibilities for cooperation".

7 No original: "To offer an effective response to these new challenges, the international legal system must be able to influence the domestic policies of states and harness national institutions in pursuit of global objectives". 
Assim, ao direito internacional que se propõe materializar políticas públicas não compete somente a ação "inter"nacional, funcionando também como um processo que emerge das e adentra nas questões "intra"nacionais em dois momentos: o bottom-up e o up-down. Slaughter Tulumello e Wood (1998) afirmam que a abordagem bottom-up complementa o foco tradicional na implementação doméstica de regras internacionais e confronta cientistas políticos e advogados internacionais com novos mundos para investigar. Assim, nesse primeiro momento, o direito internacional é o

resultado da soma do problema, da solução e dos processos políticos. Onde o problema depende dos interesses dos atores em reconhecê-los, e a solução são as ideias dos atores para resolver um problema reconhecido, enquanto o processo político corresponde ao crivo das ideias por um novo grupo de interesses (Pozzatti e Farias 2019, 366).

Para os autores, "o produto dessa soma toma a forma de atos internacionais - que apesar de dizerem muito sobre possibilidades, não são eficazes, se não quando passam a ser parte de uma nova soma" (Pozzatti e Farias 2019, 366). Se na dimensão bottom-up o ato internacional funciona como um input, na up-down ele funciona como um output, já que "nesse novo cálculo, [...] o produto da soma anterior precisa de instituições fortes. Ou seja, nela o ato internacional é fonte de instrumentos, para que as instituições do aparelho estatal construam políticas públicas” (Pozzatti e Farias 2019, 366). Dessa forma, o direito internacional passa a "condicionar os países na busca de soluções para determinados problemas comuns, através da difusão de boas práticas” (Bernardo 2016, 237).

Para entender como o direito internacional penetra a membrana estatal e se torna efetivo, Slaughter (1993) propõe justamente entendê-lo como uma política pública - ou pelo menos reconhecer aquele como um elemento do calculo desta última. Assim, a materialização do conteúdo dos tratados internacionais pode ocorrer através de "programas de ação governamental voltados à concretização de direitos" (Bucci 2001, 13).

A aproximação do direito internacional das políticas públicas como forma de traduzir o direito no vocábulo da política não é algo novo no campo (McDougal e Reisman, 1980). No entanto, reconstruir empiricamente esta dinâmica importa entender o processo pelo qual um determinado problema, ou demanda, acaba por se tornar pauta para ação do direito internacional. Isto importa conhecer os atores que estão atuando internacionalmente no fomento às políticas públicas locais, 
bem como os seus interesses e o processo político travado para implementar a sua proposta de solução. Entender este diagnóstico em um contexto geográfico e temático delimitado, importa entender quais são e de que modo determinadas instituições estabelecem diálogo entre os níveis local e global. Isto tem demandado cada vez mais do imaginário jurídico, já que “a ideia de que existe direito nacional e direito internacional, direito público e direito privado, e que a ordem jurídica é uma soma organizada dos quatro, não é mais plausível” (Kennedy 2007, 643, tradução nossa8).

As intersecções entre os dois campos se expandem ainda mais a partir da crítica construtivista, cuja abordagem considera de forma mais explícita o impacto das normas jurídicas na determinação do comportamento dos Estados e nos Estados (Slaughter 1993). Nesta perspectiva, o “mundo tal como o conhecemos é artificial, ou seja, é resultado da ação dos atores" (Souza 2006, 154), de forma que o conteúdo de categorias como direito e cooperação tem o seu conteúdo definido a partir das ações humanas que dão significado aos mesmos. Dessa forma, os interesses dos atores não estariam condicionados simplesmente pela estrutura, mas seriam eles mesmos agentes na mudança das estruturas, já que "o poder e as normas jurídicas internacionais são mutuamente constituídos” (Souza 2006, 155). É justamente este substrato construtivista que permite Slaughter (1993, 239, tradução nossa9) afirmar que “o direito informado pela política é a melhor garantia de uma política informada pelo direito”.

A partir da perspectiva liberal, Slaughter (1993) afirma que entender as relações funcionais entre os diferentes regimes permite entender ainda mais o papel do direito na política internacional. Por sua vez, Rosenau (2000) argumenta que princípios, regras e procedimentos de qualquer regime convergem para uma issue-area. Assim, é correto afirmar que emergiram inúmeros regimes de mudanças climáticas, o que leva Moravcsik (1997) a afirmar que regimes internacionais que estimulam maior cooperação possuem conjunturas próprias e particulares. Deste modo, o modus operandi desses regimes é uma variável central para a compreensão da sua ação “intra”nacional, já que

a perspectiva liberal do direito internacional sugere que as regras e normas internacionais são implementadas com mais eficácia como "compromissos horizontais" aplicados pelos tribunais e parlamentos nacionais, não como

8 No original: "The idea that there is national law and international law, public law and private law, and that the legal order is a tidy sum of the four, is no longer plausible”.

9 No original: "law informed by politics is the best guarantee of politics informed by law". 
"compromissos verticais" aplicados pelos atores supranacionais, e que tais compromissos horizontais podem gerar impulso autossustentável ao longo do tempo, capacitando grupos domésticos específicos (Moravcsik 1997, 537-538, tradução nossa10).

No entanto, a implementação dos compromissos horizontais pode esbarrar na diferenciação funcional, visto que a proliferação dos regimes temáticos pode aumentar as searas de conflitos entre eles (Young 2011). Isso é especialmente visível nos regimes ambientais, os quais frequentemente entram em colisão com regimes comerciais, por exemplo. Para dar conta dessas intersecções e conflitos, a abordagem da governança global oferta recursos analíticos extras para pensar a cooperação e o direito, visto que "o aumento da interdependência transforma o modo de fazer política, bem como os atores que participam do processo político, e que a cooperação entre os atores internacionais tem maior chance de sucesso nesse contexto que a ação unilateral" (Gonçalves e Inoue 2017, 29). Ao aumentar a interação, aumenta-se também a iteração, de onde advém o forte componente normativo e transformador dessa abordagem. Nesta perspectiva, o direito também é um aspecto constitutivo na formação dos atores e de seus interesses, visto que, justamente devido a pluralidade de atores que participam desse jogo, não há que se falar em interesses fixos.

Assim, o debate transdisciplinar permite pensar o direito internacional como um ponto de inflexão entre um primeiro jogo onde ele é visto como a síntese de um processo que institucionaliza as preferências de uma série de atores, e um segundo jogo onde ele projeta políticas públicas para materializar o conteúdo do primeiro. Isso importa reconhecer que "os processos de criação, interpretação e aplicação do direito internacional têm um impacto causal próprio nas relações internacionais, que vai além daquelas que a teoria dos regimes consegue captar" (Slaughter, Tulumello e Wood 1998, 379, tradução nossa ${ }^{11}$ ), justamente porque transbordam às questões temáticas.

No entanto, como "a demonstração de que 'tudo depende da política' não move um centímetro em direção a uma política melhor” (Koskenniemi 2009, 08,

10 No original: "the liberal account of international law [...] suggests that international rules and norms are most effectively implemented as "horizontal commitments" enforced by national courts and parliaments, not "vertical commitments" enforced by supranational actors, and that such horizontal commitments can generate self-sustaining momentum over time by empowering particular domestic groups”.

11 No original: "the process by which international law is created, interpreted and applied has a distinctive effect on international behavior that is not fully captured by regime theory" 
tradução nossa12) e o nosso objetivo não é reinventar o debate transdisciplinar dos anos 1990, cumpre buscar as lições pretendidas em um contexto espaçotemporal bastante delimitado. É o que se fará a seguir.

\section{Geografia da cooperação ambiental brasileira na América do Sul}

Esta sessão apresenta o levantamento realizado com base nos atos internacionais, e, por meio das dimensões geográficas dos regimes formados, ela informa quais são os interesses brasileiros e sul-americanos em termos de tutela do meio ambiente na região. Ressalta-se que o banco de dados que alicerça as lições seguintes foi feito a partir de critérios específicos, e, por isso, possui limites. A pesquisa foi realizada junto ao Portal Concórdia do Ministério das Relações Exteriores do Brasil (MRE) com atualização até o ano de 2019. A investigação selecionou os atos bilaterais "em vigor” firmados pelo Brasil com todos os outros Estados sul-americanos como "Parte do Acordo", o que resultou em 1681 atos. A pesquisa excluiu a Guiana Francesa, visto que o processo de adoção de atos internacionais daquele país remetia à França, e, assim, extrapolaria a delimitação territorial proposta acima.

Para afunilar os resultados para a matéria ambiental, a investigação se guiou pela busca de agendas específicas, visto inexistir no Portal Concórdia marcadores pré-estabelecidos de matérias reguladas. Dessa forma, a pesquisa orientou-se pelos marcadores expressos ao longo do corpo dos atos internacionais, a partir dos temas/marcadores disponibilizados no portal do Ministério do Meio-Ambiente (MMA). Isto permitiu concatenar os atos firmados em matéria ambiental com os temas da agenda setorial do MMA, visto que após a redemocratização do Brasil houve significativa descentralização da capacidade de formulação da política externa. Se inicialmente ela era competência quase que exclusiva do Itamaraty, a partir dos anos 1990 ela acolheu cada vez mais os interesses dos diversos grupos sociais, de forma que se aproximou das políticas públicas em diversas matérias, mimetizando muitas relações entre os níveis internacional e doméstico (Dri 2016).

O rol de documentos selecionados versa sobre a matéria ambiental de forma estrita e incidental, seguindo critérios propostos por Pozzatti e Farias (2019) em estudo semelhante, na área da saúde. Os atos “estrito” são aqueles cujo objeto

12 No original: "A demonstration that 'it all depends on politics' does not move one inch towards a better politics". 
central trata de matéria ambiental, enquanto os “incidentais" são aqueles cujo núcleo de seu conteúdo não se refere ao meio ambiente, mas que, no entanto, impactam de maneira incidental na matéria. Desse modo, foram encontrados 216 atos internacionais em vigor firmados em matéria ambiental com os países da América do Sul, sendo 79 estritos e 137 incidentais. Os 46 ajustes complementares que constam dentre esses 216 atos advêm de 16 acordos-quadro, os quais não são considerados durante a classificação dos indicadores do perfil cooperacional, pois versam apenas sobre a abertura de programas de cooperação técnica, científica ou tecnológica, e não positivavam nada em concreto na matéria ambiental.

Em relação à distribuição geográfica da cooperação ambiental brasileira na América do Sul, o Mapa 1 mostra que o Brasil possui acordos firmados com todos os países do subcontinente, não havendo adensamento de acordos em uma determinada região. O parceiro com o qual esse regime temático ganha maior densidade é a Argentina (34 atos), seguido do Uruguai (32 atos), Colômbia (30 atos), Peru (26 atos), Bolívia (20 atos), Venezuela (15 atos) Equador e Paraguai (14 atos cada), Chile (13 atos) e Guiana e Suriname (09 atos cada).

\section{Figura 1 - Distribuição geográfica (216 atos)}

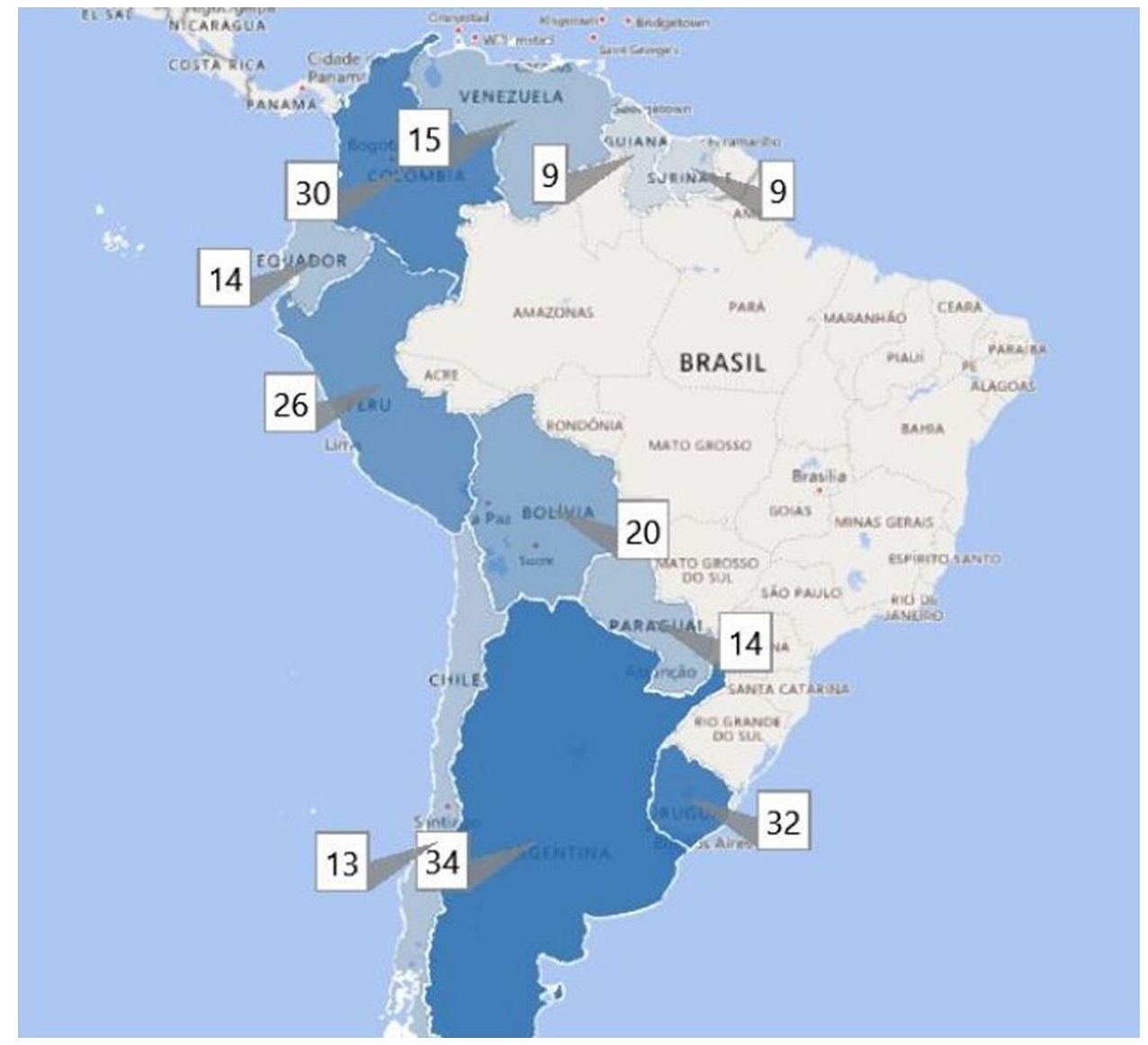

Fonte: Adaptado de MRE (2020). 
O grande alcance de países no processo de cooperação suscita questionamentos acerca da predisposição brasileira ao exercício da liderança na região. Enquanto alguns estudos, ainda que relacionados a outros temas de cooperação, apontam entre os motivos desta projeção a possibilidade de tradução de soft-power (Dri e Pittas 2017), outros apontam para o papel da burocracia estatal em projetar externamente a sua capacidade de resolução de problemas (Pozzatti e Farias 2019). Ainda, existem trabalhos que justificam a cooperação pelo fato de que, "na América do Sul, onde as guerras são raras, o poder talvez tenha um significado mais suave do que em outros lugares, e as opções políticas podem, portanto, ser estruturadas de maneira diferente" (Malamud 2011, 4, tradução nossa ${ }^{13}$ ). Investigar os motivos desta cooperação, é evidente, necessitaria outras pesquisas, a partir de outras fontes e técnicas de investigação, e foge ao escopo deste trabalho. De qualquer forma, a intensificação da cooperação não é um fenômeno exclusivo na América do Sul, visto que "as soluções para muitas questões atuais da interdependência transnacional exigirão ação coletiva e cooperação internacional” (Nye 1990, 163, tradução nossa ${ }^{14}$ ).

Quanto à dimensão temática, a análise qualitativa do acervo, sistematizada no Gráfico 1, evidencia a existência de pelo menos 10 regimes temáticos densos, composto de 3 ou mais atos internacionais agrupados a partir da temática principal - ou o principal problema que eles querem resolver. Os atos que não formaram regime, pois são únicos na temática que regulam, ou cujas disposições não são adstritas a um regime específico ou que regulam mais de uma temática concreta em matéria ambiental, foram agrupados em "Regimes Temáticos Plurais".

13 No original: "In South America, where wars have been rare, power has perhaps a softer meaning than elsewhere, and policy options may thus be framed differently".

14 No original: "The solutions to many current issues of transnational interdependence will require collective action and international cooperation”. 


\section{Gráfico 1 - Regimes temáticos (216 atos)}

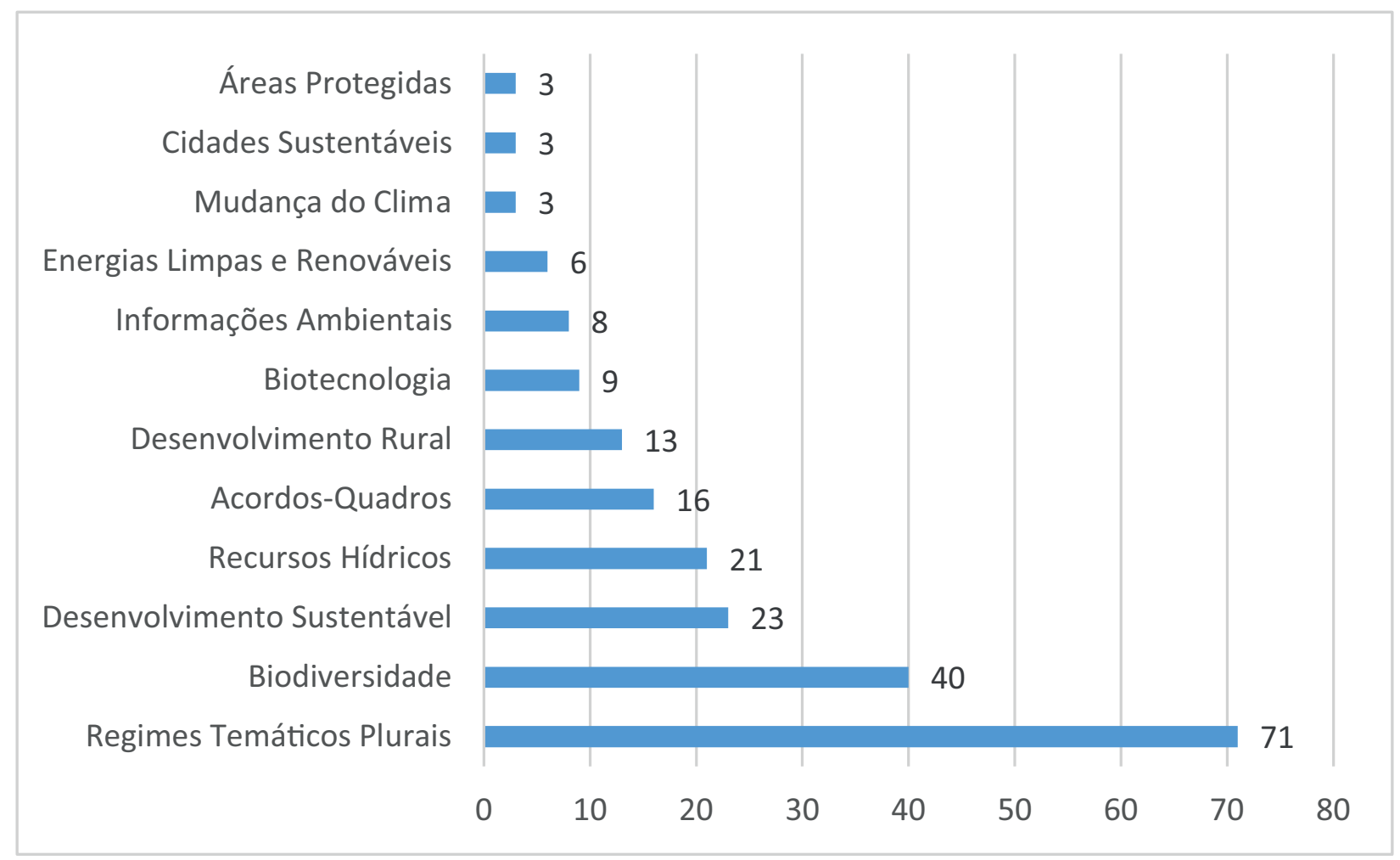

Fonte: Elaboração própria com base em MRE (2020).

Qualitativamente, evidencia-se a constituição de uma agenda difusa, permeada por um prisma multifacetado de temas regulados. O regime mais robusto - que traduz os principais problemas que os atores têm interesse em resolver - é o de Biodiversidade (40 atos), seguido pelo de Desenvolvimento Sustentável (23 atos) e de Recursos Hídricos (21 atos), o que era de se esperar se considerarmos que a América do Sul é o local de maior biodiversidade e berço da maior reserva de água potável do planeta. O que chama a atenção, no entanto, é a sobreposição destes regimes temáticos às áreas preferenciais de interesse do MMA, evidenciando a perspectiva bottom-up, no caso de a política externa brasileira emular políticas do MMA, via cooperação, ou top-down, no caso de o MMA mimetizar em nível doméstico os aprendizados de outros países. A investigação da posição do Brasil na relação, a ser investigado na próxima sessão, ajudará a esclarecer este vetor.

Ao considerar que o maior percentual de acordos é o de "Regimes temáticos plurais" (33\% dos atos analisados) e que há prevalência de tratados incidentais em meio ambiente (63\%) pode-se concluir que a cooperação ambiental transborda para além da issue-area. Assim, ao transbordar as questões temáticas, e, com isso, adensar a institucionalidade, a dinâmica do direito internacional tem um impacto causal próprio nas relações internacionais, o que parece corroborar 
com a tese de que ele funciona como um processo, na medida em que conjuga instrumentalismo com formalismo (Koskenniemi 2003).

Ao verificar o mimetismo da agenda do MMA com a agenda ambiental do MRE e também o contundente transbordamento temático envolvendo a matéria analisada, surgem alguns insights sobre o papel do direito internacional neste processo. Ao evidenciar a fragmentação do direito internacional, a abordagem da governança global expõe o funcionamento do enviesamento estrutural (structural biasis), por meio da qual “a prática jurídica vem sendo fatiada em projetos institucionais que atendem públicos especiais com interesses e princípios também especiais” (Koskenniemi 2009, 09, tradução nossa15). Desta forma, “o objetivo de criar estas instituições especializadas [ou regimes] é precisamente afetar o outcome que está sendo produzido na esfera internacional, [já que] muito pouco é totalmente aleatório por aí, como advogados praticantes sabem muito bem, direcionando seus casos para as instituições onde eles podem esperar receber a audiência mais compreensiva” (Koskenniemi 2009, 09, tradução nossa ${ }^{16}$ ).

Por sua vez, quanto à dimensão temporal do acervo de atos, o Gráfico 2 evidencia um crescimento progressivo no número de atos firmados a partir da retomada democrática. Destaca-se que no intervalo de 1990-1999 foram firmados 48 atos e, de 2000-2009, 79 atos, o que permite afirmar que a preocupação global com a proteção ambiental encontra consonância institucional na América do Sul (Dubois 2009). Contudo, pode-se inferir também que a consolidação da Onda Rosa foi um movimento significativo para a aproximação dos países do subcontinente em diversas searas, dentre elas, a ambiental (Fonseca 2011). Neste sentido, o aperfeiçoamento de políticas sociais e ambientais constitui característica importante deste fenômeno.

\footnotetext{
15 No original: "legal practice is being sliced up in institutional projects that cater for special audiences with special interests and special ethos”.

16 No original: "The point of creating such specialized institutions is precisely to affect the outcomes that are being produced in the international world. Very little is fully random out there, as practising lawyers know very well, directing their affairs to those institutions where they can expect to receive the most sympathetic hearing".
} 


\section{Gráfico 2 - Data de assinatura (216 atos)}

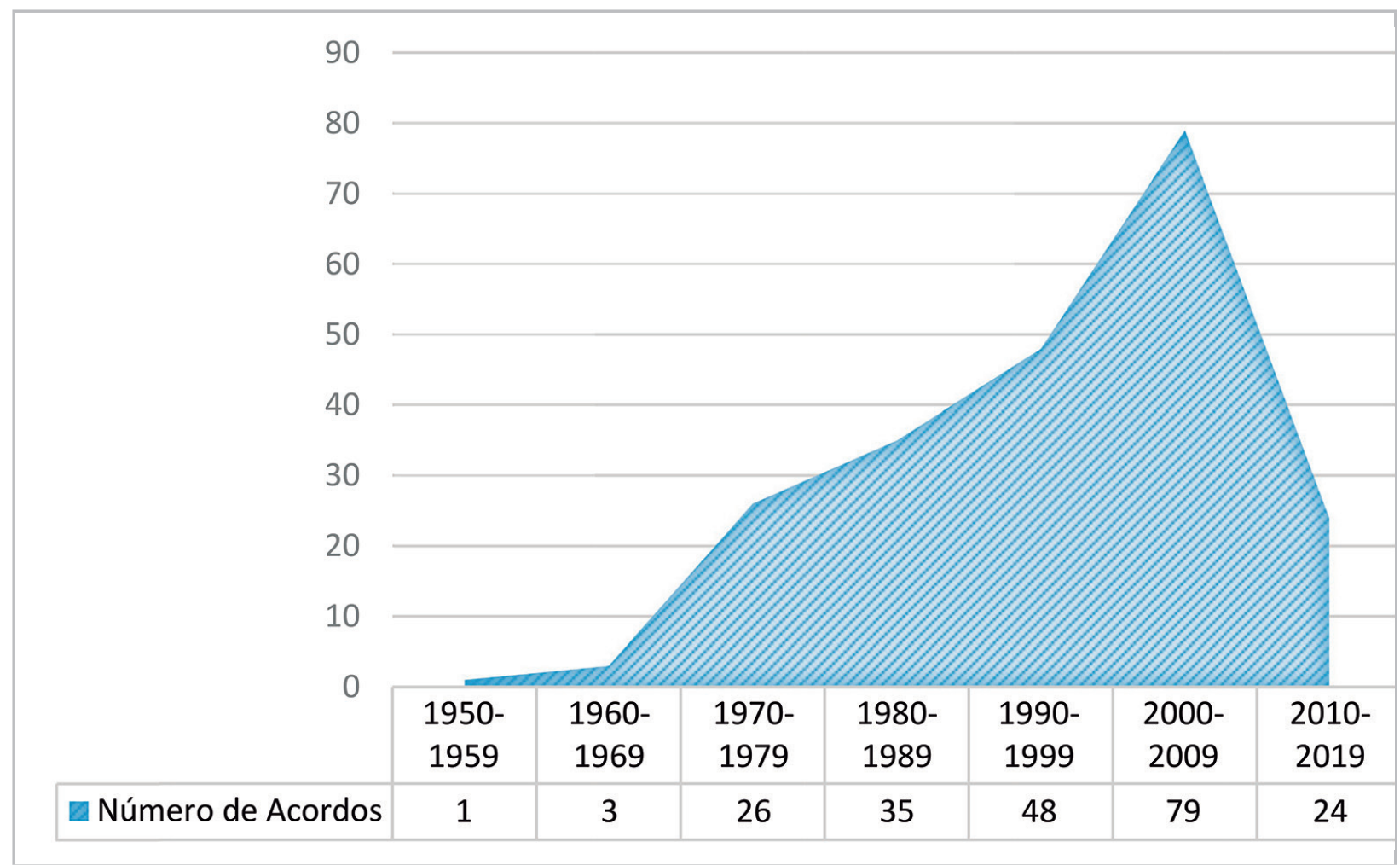

Fonte: Elaboração própria com base em MRE (2020).

O maior número de atos firmados na primeira década dos anos 2000 possui correspondência direta com o projeto de política externa instituído a partir da eleição de Lula da Silva (Fonseca 2011). Ao passo que a conjuntura regional propiciava maior homogeneidade no espectro político da região, outras variáveis emergiam no cenário internacional. Assim, "se o primeiro mandato de Lula, em 2003, começou com a afirmação da importância da América do Sul e da região, rapidamente as relações extra-regionais se sobrepuseram a essas, devido às vantagens que apresentavam para a afirmação internacional do Brasil" (Fonseca 2011, 41), diminuindo progressivamente o número de atos assinados em meio ambiente a cada ano. Mas se, até 2018, o Brasil ainda firmava atos de cooperação em matéria ambiental, atualmente o contexto político brasileiro mudou drasticamente. O governo Bolsonaro, a partir de 2019, desestruturou políticas públicas de preservação da biodiversidade conduzidas pelo IBAMA e ICMBio e perdoou diversas infrações ambientais, o que denota a pouca importância dessa pauta no seu governo, e a correspondente indisposição em promover a cooperação regional nessa matéria.

Esta sessão mostrou quais ideias resistiram aos embates políticos e materializaram-se em soluções para os problemas pelos quais os atores manifestaram 
interesses. A análise da geografia evidencia que a cooperação ambiental alcança um rol extenso de países na América do Sul, performando uma agenda difusa que teve o seu apogeu na primeira década dos anos 2000. A próxima sessão investiga a arquitetura desta cooperação para mensurar o padrão do seu funcionamento e inferir o papel do direito internacional neste processo.

\section{Arquitetura da cooperação e a possibilidade de construção de políticas públicas}

Para pensar como a cooperação internacional impacta o processo político doméstico, e explorar o papel do direito internacional nesse percurso, é necessário investigar o que os atores estão dispostos a aportar ao projeto cooperativo, e pensar isto exige uma joint discipline, pois "essa abordagem rejeita a simples dicotomia direito/poder e, ao invés disso, argumenta que regras e normas operam mudando os interesses e, assim, remodelando os objetivos pelo qual poder é exercido" (Slaughter, Tulumello e Wood 1998, 381, tradução nossa17). Dessa forma, para construir o panorama sugerido por Abbott (1989), soma-se ao contexto geográfico, analisado anteriormente, de onde se inferem as condições estruturais nas quais opera o direito, a identificação das técnicas e das estratégias implementadas pelos atores.

Para formular os indicadores da investigação qualitativa, partiu-se das dimensões do sucesso da cooperação identificadas por Axelrod e Keohane (1985) e dos indicadores adotados por Pozzatti e Farias (2019) para analisar a cooperação sanitária na América do Sul, a qual também se insere no âmbito da cooperação Sul-Sul (CSS) e difere, ao menos em tese, com a clássica cooperação internacional para o desenvolvimento, de vetor Norte-Sul (Burges 2012). Em função das dinâmicas dessa cooperação em setores específicos, optamos pelos seguintes indicadores, que também são claros marcadores de horizontalidade: "distribuição dos encargos financeiros", "posição na relação", "consenso na publicidade" e "formas de avaliação". Estes indicadores permitem inferir sobre a circularidade entre instrumentalismo e formalismo que caracteriza o direito internacional entendido como um processo de articulação entre as esferas domésticas e internacionais (Koskenniemi 2003).

17 No original: “This approach rejects a simple law/power dichotomy, arguing instead that legal rules and norms operate by changing interests and thus reshaping the purposes for which power is exercised”. 
A partir da "aldeia" delimitada na sessão anterior, fez-se um recorte dos 79 atos estritos em matéria ambiental para, através da analise qualitativa dos mesmos, tirar algumas lições sobre este processo. O primeiro indicador diz respeito à “distribuição dos encargos financeiros", o qual, para Axelrod e Keohane (1985), é central para a consolidação da cooperação, o que parece ser especialmente decisivo no contexto Sul-Sul, em que um Estado dificilmente tem condições de arcar sozinho com os custos da cooperação. A analise qualitativa verificou que 35 atos dispõem de uma divisão expressa de custos, ao passo que 44 deles não versam acerca dessa divisão ou expressamente se isentam mutuamente destes custos. Cabe destacar que nenhum dos atos analisados dispunha de um Estado como único ou principal fonte de financiamento, o que sugere que a estrutura de pagamento se insere em uma lógica de CSS, atendendo ao princípio de horizontalidade. Ainda, a não existência de uma política de paymaster em meioambiente encontra-se em consonância com o standard da cooperação brasileira em matéria sanitária para a região (Pozzatti e Farias 2019).

O desempenho ou não da função de paymaster também se relaciona com o papel dos atores no que tange à "posição na relação", indicador que ajuda a compreender se há horizontalidade no projeto cooperacional ou se, por outro lado, há agentes capacitantes e agentes capacitados. Dos 79 atos analisados, 09 deles preveem atividades de capacitação em conjunto, 33 positivam o Brasil como agente capacitante e em nenhum deles o Brasil ocupa o papel de agente capacitado. Ademais, 37 atos não preveem qualquer ação de capacitação ou não há qualquer informação sobre posição na relação. Dessa forma, ainda que não se possa ignorar certa horizontalidade, os resultados evidenciam uma liderança técnica do Brasil na matéria ambiental. Para Schmitz e Rocha (2017), tal posição é representativa de uma tentativa de protagonismo do país:

O Brasil é um importante ator no processo de adensamento e reformulação de políticas de governança global. O país não possui capacidade material ou vontade política para fazer valer suas posições na cena global. Vale-se, no entanto, com bastante recorrência, de sua habilidade como ator político de influenciar indiretamente o comportamento ou os interesses de outros atores da comunidade por meios culturais ou ideológicos. Adensar, fortalecer, reformar e traçar uma melhor inserção nos processos de governança global devem ser uma prioridade (Schmitz e Rocha 2017, 19).

É importante conceber a inter-relação entre os dois marcadores previamente analisados: ao passo que o Brasil exerce certa liderança técnica nos atos de 
meio-ambiente através de uma posição de agente capacitador, não dispõe de uma política de paymaster nestes projetos. Esses dados sugerem que o Brasil se compromete com a cooperação na região na medida em que isso não envolve alocação de recursos financeiros. As evidências sugerem estar correta a ideia de que "ao jogar a carta regional para alcançar objetivos globais, o Brasil acabou em uma situação inesperada: enquanto sua liderança regional cresce no papel, na prática encontra uma resistência crescente” (Malamud 2011, 19, tradução nossa18).

Ainda quanto aos dois primeiros marcadores, foi verificado que em diversos atos as partes referem-se mutuamente como parceiros, e não como doador e receptor. A percepção dos atores em relação à reciprocidade e horizontalidade dos outros possui uma centralidade para o seu compromisso na cooperação, de forma que não somente os fatores práticos, mas também os subjetivos, têm importância (Axelrod e Keohane 1985). A reciprocidade ocupa um papel central na promoção da aproximação entre os atores, o que indica uma possível prevalência de sucesso na cooperação bilateral, objeto desta investigação empírica.

Uma análise qualitativa das posições na relação previstas nos atos evidencia que o fortalecimento institucional é objeto preferencial desta cooperação ambiental, atravessando os diversos regimes temáticos. É expressivo o número de Ajustes Complementares cujo objetivo é “fortalecer”19 diversos órgãos nacionais responsáveis pela tutela ambiental ou o "desenvolvimento de capacidades” 20 locais. Dessa forma, não é incorreto afirmar que a cooperação analisada é arquitetada de forma a estruturar sistemas conjuntos de proteção ambiental (envolvendo política pública transnacional) e, em algum grau, capacitar os sistemas nacionais dos países envolvidos (emulando políticas públicas locais).

Em relação ao espaço geográfico em que o Brasil atua como agente capacitante, uma analise interseccional dos dados revela que dos 33 atos em que o Brasil é agente capacitante, a América Andina é o foco de $64 \%$ deles, o Suriname e a Guiana juntos concentram $24 \%$, enquanto o Cone-Sul concentra os outros $12 \%$.

18 Do original: By playing the regional card to achieve global aims, Brazil has ended up in an unexpected situation: while its regional leadership has grown on paper, in practice it has met growing resistance.

19 Por exemplo, o “Ajuste Complementar ao Acordo Básico de Cooperação Técnica entre o Brasil e o Equador para implementação do Projeto Apoio a criação de um sistema de informação nacional de recursos hídricos florestais", firmado em 18/02/2011, tem por finalidade “fortalecer a Secretaria Nacional das Águas equatoriana, por meio de cursos de capacitação para o desenvolvimento de pesquisas em hidrologia florestal e para a implementação de um Sistema de Informação Nacional de Recursos Hídricos” (MRE 2020).

20 Por exemplo, o "Ajuste Complementar ao Acordo de Cooperação Técnica entre o Brasil e a Argentina para implementação do projeto "Desenvolvimento de capacidades na área de gestão de recursos hídricos”, firmado em 21/02/2008 (MRE 2020). 
Em relação ao período, dos 33 atos, a maior parte foi firmada entre 2000-2009 (22 atos) e entre 2009-2018 (10 atos). No que se refere a capacitação mútua, o Cone-Sul representa $67 \%$ dos atos que vislumbram este marcador, em que pese componha 39\% dos atos em relação ao total de atos estritos. Dos 09 atos nos quais há capacitação mútua, 4 são com a Argentina, 2 com o Peru, 2 com o Uruguai e 1 com a Bolívia.

A proeminência na cooperação para fortalecimento institucional (42 atos) sugere a existência de uma cooperação estruturante em matéria ambiental. Este conceito deriva da experiência da cooperação em saúde, através de bases comuns que fomentavam uma interação horizontal entre os atores, "no panorama do que hoje vem sendo aplicado como capacity building por estar direcionada para o treinamento de recursos humanos e a construção de capacidades" (Ferreira e Fonseca 2017, 2130). A existência deste fenômeno revela a forma como o direito internacional, ao institucionalizar a cooperação estruturante, pode impulsionar políticas públicas locais, já que:

mais que oferecer assessorias diretas por especialistas estrangeiros ou trocas de 'experiências' e 'boas práticas', implica no esforço dos responsáveis locais, para que, com possível orientação externa, possam participar no processo de introdução das transformações necessárias para o aprimoramento pretendido (Ferreira e Fonseca 2017, 2131).

A avaliação deste aprimoramento, no entanto, fica prejudicada quando analisada a "forma de avaliação" das atividades da cooperação, as quais podem ser atividades de monitoramento ou de avaliação. Do acervo, 39 atos preveem avaliações não periódicas e apenas 10 deles referem-se a avaliações periódicas (monitoramento). Ainda, 30 atos não fazem qualquer referência a estes mecanismos. Tal indicador evidencia o reduzido nível de acompanhamento das atividades e suscita o questionamento sobre de que maneira a cooperação internacional pode ser efetiva e projetar sombra para o futuro se não há uma metodologia aplicada à avaliação.

Por fim, o último indicador analisado diz respeito ao "consenso na publicidade" dos relatórios de avaliação das atividades decorrentes do ato internacional, e informa sobre a transparência dos atores envolvidos em evidenciar os seus interesses visíveis na empreitada cooperacional. Em 44 atos consta a previsão do consenso ao passo de que 35 não contêm informações relativas a este indicador, permitindo às partes a ampla e livre divulgação de quaisquer resultados e para 
qualquer fim. Em que pese haja preponderância de horizontalidade, o que impacta positivamente na percepção dos atores sobre a mutualidade dos interesses também nas estratégias de comunicação, é considerável o número de atos que não investem em estratégias para regular este indicador. O Gráfico 3 sintetiza os resultados do levantamento realizado.

\section{Gráfico 3 - Indicadores de horizontalidade (79 atos)}

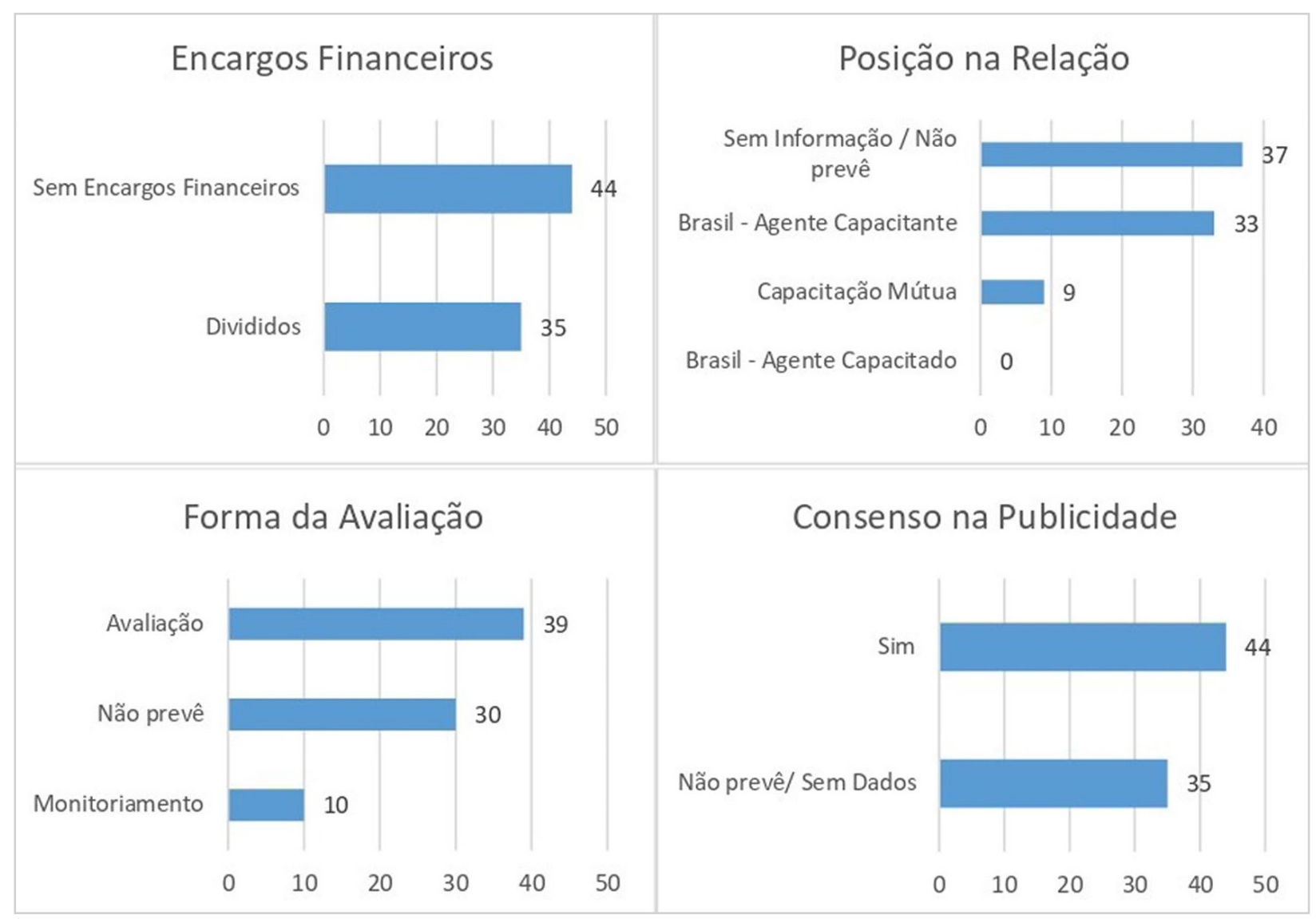

Fonte: Elaboração própria com base em MRE (2020).

Pelos dados produzidos, é possível traçar a arquitetura da cooperação ambiental brasileira na América do Sul. Apesar da proeminência de horizontalidade, o que indica a solidez das empreitadas de construção de políticas públicas transversais e, talvez, a transferência delas por parte do Brasil, a baixa incidência de mecanismos de monitoramento poderia sugerir que a cooperação seria altamente retórica. Ainda, cerca de $43 \%$ dos atos preveem o Brasil como agente capacitante, evidenciando o seu possível papel em emular políticas públicas na região, ao mesmo tempo que o Brasil não exerce a política de paymaster na região.

Ao constatar a grande incidência de atos que envolvem capacitação (seja unilateral ou mútua), e, portanto, contribuem com o fortalecimento institucional, 
verifica-se que a cooperação ambiental tem significativo perfil estruturante. Isso encontra respaldo em outras pesquisas feitas em outros setores, as quais constatam que CSS brasileira não se baseia em vastas doações de recursos financeiros, mas na transferência de um conjunto de conhecimentos e soluções técnicas que tiveram um impacto positivo no desenvolvimento brasileiro e que podem ser replicados em países com desafios semelhantes (Pozzatti e Farias 2019). Assim, pode-se inferir que a cooperação opera mudanças institucionais nos Estados envolvidos, as quais podem repercutir no aprimoramento de políticas públicas locais. Para Burges,

O elemento interessante da cooperação Sul-Sul é que em vários casos as agências que costumavam coordenar os fluxos de entrada da cooperação para o desenvolvimento estão agora sendo utilizadas para organizar as saídas. Em alguns casos, isso significou apenas pequenas mudanças institucionais, muitas vezes dentro dos Ministérios das Relações Exteriores, mas em outros, resultou em um fortalecimento significativo das instituições internacionais de cooperação e na discussão do estabelecimento de agências de desenvolvimento permanentes [...] (Burges 2012, 249).

Dessa forma, as instituições que antigamente operavam basicamente o output dos processos políticos cujo input era performado no Norte global, hoje estão elas mesmo jogando os dois jogos (Pozzatti e Farias 2019). E isso é revolucionário porque o resultado advindo das mudanças na atuação do direito internacional na contemporaneidade - nas fronteiras entre as esferas doméstica e internacional, que agora se cruzam e até conflitam - "será jogos de dois níveis cada vez mais elaborados, mas cada jogo permanecerá em seu próprio tabuleiro, não importando o quão complexos e densos sejam os elos entre eles" (Slaughter e Burke-White 2006, 350, tradução nossa21).

Deste modo, constata-se que a cooperação é um elemento chave para a proteção ambiental, visto que o direito internacional que a operacionaliza, ao estruturar os regimes protetivos do meio ambiente, tem uma dupla função: internacional e intranacional. Pela perspectiva “inter"nacional o direito tutela os interesses preponderantes dos atores públicos e privados desta esfera, bem como sintetiza a mutualidade de interesses acerca de como é possível mobilizar a organização social e política para tratar das questões que ele ilumina. Por sua

21 No original: "Will be ever more elaborate two-level games, but each game will remain on its own board, no matter how complex and dense the links between them". 
vez, na perspectiva “intra”estatal o direito projeta a construção ou a melhora de políticas públicas locais para dar viabilidade aos valores e interesses tutelados pelos acordos.

A partir da substancial horizontalidade que caracteriza o regime analisado, percebe-se que a cooperação internacional em setores específicos contribui com o enviesamento estrutural, o que é exatamente a função do direito internacional entendido a partir da joint discipline. Nesta perspectiva, ele não exerce uma função gerencial, pois não vem de cima e constrange os Estados. Ao contrário, participando do enviesamento estrutural, o direito internacional se torna um processo de articulação das condições de possibilidade de conciliação dos interesses dos diversos atores envolvidos. Por isso, os indicadores de horizontalidade dizem muito sobre a sua possibilidade de atuar como um processo que, ao mesmo tempo que é uma ferramenta do poder, cria e delimita poder (Koskenniemi 2003). Assim, o direito internacional tende a ser mais efetivo quanto mais for capaz de operacionalizar a mutualidade de interesses dos atores envolvidos.

Contudo, é preciso avançar no que tange ao acesso das informações dos atos internacionais firmados pelo Brasil. Mesmo que o Portal Concórdia possua um acervo significativo de acordos em sua base de dados, o mesmo apresenta classificações temáticas inadequadas. Ademais, a indisponibilidade de informações relativas aos projetos de execução firmados pelos Estados no âmbito desses acordos constitui-se um entrave para o aprofundamento da investigação. Uma eventual avaliação dos impactos últimos desses atos internacionais na execução de políticas públicas necessitaria destas outras fontes ou de relatórios de resultados, além, é evidente, do uso de metodologias de pesquisa distintas da documental, como as entrevistas.

\section{Conclusão}

Uma joint discipline surge quando há a formação de um campo de conhecimento novo, a partir da superação dos níveis da interdisciplinaridade. Nesse sentido, ao transpassar as disciplinas de RI e DI, o estudo da geografia e da arquitetura da cooperação ambiental brasileira na América do Sul a partir das evidências do direito internacional, e justamente inquirindo o seu papel neste processo, é uma empreitada para o qual a transdisciplinaridade pode ser invocada. A abordagem aqui proposta não transpôs simplesmente os resultados 
da disciplina legal ou política para o outro lado, ou traduziu os seus vocábulos e métodos. Ao contrário, o diagnóstico proposto só foi possível a partir do abandono da ideia de que existem lados (e, portanto, disciplinas primárias) e que a governança ambiental regional possível (e positivada nos atos) é fruto de uma circularidade constitutiva que agrega dimensões legais e políticas.

Assim, o panorama proposto por Abbott (1989) foi desdobrado no estudo da geografia e da arquitetura da cooperação, o que nos permitiu diagnosticar, respectivamente, as condições estruturais que favorecem ou entravam a cooperação internacional e as técnicas usadas pelos atores para alcançar a cooperação e as estratégias para modificar condições prevalentes. A partir dessa dupla dimensão, foram apreendidas algumas lições de como o direito internacional opera para, através da cooperação internacional, fomentar políticas públicas.

A análise quantitativa da geografia cooperacional evidenciou que ela alcança todos os países da América do Sul, performando uma agenda difusa que teve o seu apogeu na primeira década dos anos 2000. Os 216 atos analisados materializam 10 regimes temáticos densos dentro da matéria ambiental, o que sugere forte demanda por políticas públicas regionais. Somando-se isso ao mimetismo verificado entre estes regimes e a agenda do MMA, infere-se que cada ato é a síntese, ou o input, do embate político travado pelos diversos grupos sociais preocupados com o tema em voga. Assim, a cooperação internacional emerge como importante mecanismo de articulação entre os interesses congruentes dos atores subnacionais em questão.

O exame da arquitetura da cooperação permitiu a identificação das técnicas e estratégias utilizadas pelos atores de como implementar o que foi positivado. Dos 79 atos submetidos à investigação qualitativa, em 35 deles há uma distribuição horizontal dos encargos financeiros, ao passo que em 33 atos há a presença do Brasil como agente capacitante. No entanto, se é verdade que o Brasil exerce certa liderança técnica nos atos de meio-ambiente, o país não dispõe de uma política de paymaster nestes projetos, o que sugere relevante horizontalidade na empreitada cooperacional. Ainda, 49 atos preveem expressamente formas de avaliação e monitoramento e em 44 deles há previsão do consenso na publicidade destes relatórios, o que acentua a horizontalidade do perfil cooperacional.

Somando as duas dimensões, infere-se que o direito internacional fomenta - através da cooperação - políticas públicas, na medida que ele se coloca como um processo que articula o input e o output. Dessa forma, para além de ser simples objeto de estudo da ciência política, ele desempenha importante papel 
normativo, com forte potencial transformador da realidade social. Os resultados da investigação sugerem que o direito internacional opera políticas públicas na medida que atua como um processo circular que agrega as dimensões “inter”nacional e “intra”nacional, as quais pavimentam o caminho para a efetivação de um direito, “desde o seu nascimento, quando é previsto na norma, até a sua emancipação, quando é encartado em determinado programa de ação de um governo e passa a integrar medidas de execução” (Bucci 2001, 12).

\section{Referências}

Abbott, Kenneth W. 1989. Modern International Relations Theory: a prospectus for international lawyers. Yale Journal of Internationnal Law, v. 14: 335-411.

Axelrod, Robert; Keohane, Robert O. 1985. Achieving cooperation under anarchy: Strategies and Institutions. World Politics, v. 38, no. 1: 226-254.

Barnett, Jon; Adger, W. Neil. 2007. Climate change, human security and violent conflict. Political Geography, v. 26, no.6 : 639-655.

Barros-Platiau, Ana F.; Varella, Marcelo D.; Schleicher, Rafael T. 2004. Meio ambiente e relações internacionais: perspectivas teóricas, respostas institucionais e novas dimensões de debate. Revista Brasileira de Política Internacional, v. 47, n. 2: 100-130.

Bernardo, Glaucia J. 2016. Organizações internacionais como agentes de transferência e difusão de políticas públicas. Conjuntura Global, v. 5, no. 2: 233-252.

Bucci, Maria Paula D. 2001. "Buscando um conceito de políticas públicas para a concretização dos direitos humanos”. In Direitos Humanos e políticas públicas. (Bucci, Maria Paula D.), 05-16. São Paulo: Pólis.

Burges, Sean. 2012. Desenvolvendo a partir do sul: cooperação sul-sul no jogo de desenvolvimento global. Austral: Revista Brasileira de Estratégia e Relações Internacionais, v. 1, no. 2: 237-263.

Dri, Clarissa F. 2016. Demanda e oferta de bens públicos regionais: políticas públicas transnacionais na América do Sul? Revista de Iniciação Científica em Relações Internacionais, v. 3, no. 6: 1-8.

Dri, Clarissa F.; Pittas, Tiago M. 2017. O diálogo entre saúde e política externa na cooperação brasileira em bancos de leite humano. Revista Ciência \& Saúde Coletiva, v. 22, no. 7: 2277-2286.

Dubois, Sandrine Maljean. 2009. “A Implantação do Direito Internacional do MeioAmbiente”. In Proteção Internacional do Meio-Ambiente. (Varella, Marcelo D.; Barros-Platiau, Ana Flávia), 89-121. Brasília: Unitar, Uniceub e Unb. 
Ferreira, José R.; Fonseca, Luiz E. 2017. Cooperação estruturante, a experiência da Fiocruz. Ciência \& Saúde Coletiva, v. 22, no. 7: 2129-2133.

Fonseca, Carmem. 2011. A política externa brasileira da democracia: o paradoxo da mudança na continuidade?. Revista R:I Relações Internacionais, v. 29, no. 29: 33-43. Gonçalves, Veronica K.; Inoue, Cristina Y. 2017. “Governança Global: Uma ferramenta de análise”. In Brasil e o Sistema das Nações Unidas: desafios e oportunidades na governança global. (Schmitz, Guilherme O.; Rocha, Rafael A.), 27-58. Brasília: Ipea. Kennedy, David. 2007. One, two, three, many legal orders: legal pluralism and the cosmopolitan dream. NYU Review of Law \& Social Change, v. 31, no.3: 641-659.

Keohane, Robert. 2002. "International Relations and International Law: two optics”. In Power and Governance in a Partially Globalized World. (Keohane, Robert), 117-130. New York: Routledge.

Koskenniemi, Martti. 2009. The Politics of International Law. 20 Years later, EJIL, v. 20, no. 1: 04-32.

Koskenniemi, Martti. 2003. “What is international law for?”. In International Law (Evans, Malcolm), 32-57. Oxford: UP.

Krasner, Stephen D. 2012. Causas estruturais e consequências dos regimes internacionais: Regimes como variáveis intervenientes. Rev. Soc. Política, v. 20, no. 42: 93-110.

Malamud, Andrés. 2011. A Leader Without Followers? The Growing Divergence Between the Regional and Global Performance of Brazilian Foreign Policy. Latin American Politcs and Society, v. 53, no. 3: 1-24.

McDougal, Myres S.; Reisman, W. Michael. 1980. The prescribing function in World Constitutive Process: how international law is made. Yale Studies in World Public Order, v. 06, no. 02:249-284.

Moravcsik, Andrew. 1997. Taking Preferences Seriously: A Liberal Theory of International Politics. International Organization, v. 51, no. 4: 513-553.

Ministério das Relações Exteriores. 2020 Concórdia. Acervo de atos internacionais do Brasil. Disponível em: https://concordia.itamaraty.gov.br/ Acesso em 01 mar. 2020. Nye, Joseph S. 1990. Soft Power. Foreign Policy, no. 80: 153-171.

Pozzatti, Ademar; Farias, Luiza. 2019. O Brasil e a cooperação Sul-Americana em saúde: dos regimes temáticos às possibilidades de efetivação estruturante. Revista de Direito Internacional, v. 16, no. 2: 363-382.

Queiroz, Julia M. 2011. Desenvolvimento econômico, inovação e meio ambiente: a busca por uma convergência no debate. Cadernos do Desenvolvimento, v. 6, no. 9: 143-170. Rosenau, James N. 2000. “Governança, ordem e transformação na política mundial”. In Governança sem governo: ordem e transformação na política mundial, 11-46. Brasília: Unb. 
Schmitz, Guilherme de O.; Rocha, Rafael A. 2017. "Desafios e oportunidades para o brasil na governança global: uma breve introdução”. In Brasil e o Sistema das Nações Unidas: desafios e oportunidades na governança global. (Schmitz, Guilherme de O.; Rocha, Rafael A.), 11-26. Brasília: Ipea.

Slaughter, Anne-Marie.1993. International Law and International Relations Theory: a Dual Agenda. American Journal of International Law, v. 87, no. 2: 205-239.

Slaughter, Anne-Marie; Tulumello, Andrew S.; Wood, Stepan. 1998. International Law and International Relations Theory: a New Generation of Interdisciplinary Scholarship. American Journal of International Law, v. 92, no. 3: 367-397.

Slaughter, Anne-Marie; Burke-White William. 2006. The Future of International Law Is Domestic (or, The European Way of Law). Harvard International Law Journal, v. 47 , no. 2: 327-352.

Souza, Igor Abdalla M. 2006. Dom Quixote reencontra Sancho Pança: relações internacionais e direito internacional antes, durante e depois da Guerra Fria. Rev. Contexto Internacional, v. 28, no. 01:101-166.

Young, Oran R. 2011. Effectiveness of international environmental regimes: Existing knowledge, cutting-edge themes, and research strategies. Pnas, v. 108, no. 50: 19853-19860. 